\title{
Development and Validation of the Therapeutic Education for Diabetes Self-Care Behavior Scale
}

\author{
Construção e Validação da Escala de Educação Terapêutica para o Comportamento de \\ Autocuidado na Diabetes \\ Construcción y Validación de la Escala de Educación Terapéutica para el Comportamiento \\ del Autocuidado en la Diabetes
}

Eva Patrícia da Silva Guilherme Menino*; Maria dos Anjos Coelho Rodrigues Dixe**;

Maria Clarisse Carvalho Martins Louro***

\begin{abstract}
Background: The adoption of self-care behaviors by the person with diabetes is an outcome-determining factor, and education for self-care is an effective nursing intervention within this context.

Objectives: To develop and validate the Therapeutic Education for Diabetes Self-Care Behavior Scale.

Methodology: This methodological study was conducted on a sample of 104 nurses working in primary health care. The international guidelines were followed in the development and validation of the scale.

Results: The analysis of the reliability of the six dimensions (healthy eating, being active, monitoring, taking medication, problem solving and healthy coping, and reducing risks) showed Cronbach's $\alpha$ values ranging between 0.768 and 0.933 . Correlation matrices $(p>0.001)$ and the Kaiser-Meyer-Olkin measures greater than 0.7 in all dimensions/subscales ensure reasonable adequacy of the factorial model of each dimension (subscale).

Conclusion: The multidimensional scale is valid and reliable for assessing the frequency with which nurses provide therapeutic education on self-care behaviors to the person with diabetes.
\end{abstract}

Keywords: health education; diabetes; validation studies; nursing

\section{Resumo}

Enquadramento: A adoção de comportamentos para 0 autocuidado por parte da pessoa com diabetes é determinante nos resultados, sendo a educação para o autocuidado uma intervenção de enfermagem eficaz neste sentido.

Objetivos: Construir e validar a Escala Educação Terapêutica para o Comportamento de Autocuidado à Pessoa com Diabetes (ETCAD). Metodologia: Estudo metodológico, com amostra de 104 enfermeiros que trabalham em cuidados de saúde primários. Para a construção e validação da escala seguiram-se as guidelines internacionais.

Resultados: Os resultados da análise da fidelidade das 6 dimensões: alimentação saudável, manter-se ativo, monitorização, medicação, resolução de problemas e coping saudável e redução dos riscos, apresentam valores de $\alpha$ de Cronbach que variam entre 0,768 e 0,933 . As matrizes de correlação $(p>0,001)$ e as medidas de Kaiser-Meyer-Olkin superiores a 0,7 em todas as dimensões/ subescalas garantem a adequação razoável do modelo fatorial de cada dimensão (subescala).

Conclusão: A escala multidimensional é válida e fiável para avaliar a frequência com que os enfermeiros realizam educação terapêutica sobre os comportamentos de autocuidado à pessoa com diabetes.

Palavras-chave: educação em saúde; diabetes; estudos de validação; enfermagem

\footnotetext{
* Ph.D., 2nd Triennium Assistant, Polytechnic Institute of Leiria, School of Health Sciences, 2411-901, Leiria, Portugal [eva.guilherme@gmail.com]. Contribution to the article: article writing, literature search, data collection, data analysis and discussion. Address for correspondence: Rua de Ourém, Lote 10, $4^{\circ} \mathrm{A}$ Edifício Praça Nova, 2415-781, Marrazes, Leiria, Portugal.

* Ph.D., Coordinating Professor, Polytechnic Institute of Leiria, School of Health Sciences, 2411-901, Leiria, Portugal [maria.dixe@ipleiria.pt]. Contribution to the article: statistical treatment and assessment, data analysis and discussion.

**** Ph.D., Adjunct Professor, Polytechnic Institute of Leiria, School of Health Sciences, 2411-901, Leiria, Portugal [clarisse.louro@ipleiria.pt].Contribution to the article: data collection, analysis and discussion.
}

\section{Resumen}

Marco contextual: La adopción de conductas de autocuidado por parte de la persona con diabetes es determinante en los resultados. A este respecto, la educación para el autocuidado es una intervención de enfermería eficaz.

Objetivos: Construir y validar la escala Educação Terapêutica para o Comportamento de Autocuidado à Pessoa com Diabetes (ETCAD).

Metodología: Estudio metodológico llevado a cabo en una muestra de 104 enfermeros que trabajan en atención primaria de salud. Para la construcción y validación de la escala se siguieron las directrices internacionales.

Resultados: Los resultados del análisis de la fidelidad de las 6 dimensiones: alimentación saludable, mantenerse activo, monitorización, medicación, resolución de problemas y de afrontamiento sano y reducción de riesgos presentan valores de alfa de Cronbach que varían entre 0,768 y 0,933 . Las matrices de correlación ( $p<0,001)$, así como las medidas de Kaiser-Meyer-Olkin superiores a 0,7 en todas las dimensiones / subescalas garantizan una adecuación razonable del modelo factorial de cada dimensión (subescala).

Conclusión: La escala multidimensional es válida y fiable para evaluar la frecuencia con la que los enfermeros realizan educación terapéutica sobre los comportamientos de autocuidado de la persona con diabetes.

Palabras clave: educación en salud; diabetes; estudios de validation, enfermería

Received for publication: 18.09 .15

Accepted for publication: 21.01.16 


\section{Introduction}

The diagnosis of diabetes often requires extensive lifestyle changes, behavioral changes, and the development of self-care skills (Hollis, Glaister, \& Lapsley, 2014).

Diabetes Self-Management Education (DSME) is the cornerstone of an effective care in this area (Haas et al., 2014), with the guidelines on DSME issued by the American Diabetes Association being widely recognized and applied (Menino, Dixe, Louro, \& Roque, 2013).

Although a set of principles and guidelines is presumed to be at the basis of all the implemented programs, it is acknowledged that there is a wide variability in the practices, in particular regarding the length, contents and educational styles of the programs aimed at the education of patients with diabetes. For example, in the United Kingdom, some of the educational programmes offered are unstructured, very few have been formally evaluated, and few professionals who deliver therapeutic education have been formally trained for this purpose, thus questioning the effectiveness achieved with different practices and which practices are associated with better outcomes (National Institute for Clinical Excellence, 2003).

In the area of diabetes, the importance of nurses giving visibility to their contribution in self-care education and promotion as a specific focus and outcome of their care has been highlighted, as their role in the management of chronic diseases has been increasingly recognized. As it is important to assess the effectiveness of these programs and, more specifically, to understand the nurses' interventions on therapeutic education for self-care, we have searched for valid instruments for assessing the therapeutic education interventions developed by nurses aiming at the person with diabetes. We decided to conduct this study because we found no instruments specifically designed for this purpose in the literature. The issue referring to the impact of diabetes at various levels justifies the need to develop and validate a scale to assess the frequency with which nurses develop therapeutic education interventions for self-care behavior aiming at the person with diabetes, since these interventions have yielded health benefits.

This methodological study was conducted with the purpose of building the Therapeutic Education for
Diabetes Self-Care Behavior Scale and assessing its psychometric characteristics.

\section{Background}

Diabetes mellitus is a significant chronic disease which, according to the International Diabetes Federation (IDF; 2013), affects more than 371 million people worldwide, being currently considered an epidemic. Portugal has one of the highest prevalence rates in Europe: in 2011, 12.7\% of the population aged between 20 and 79 years (Correia et al., 2013) had diabetes, which is a leading cause of death in Portugal (4.5\% in 2012).

Diabetes is a chronic disease that persists throughout life and impacts almost every aspect of life. Living with diabetes is complex and the main therapeutic measures relate to self-care and lifestyle changes, which are often necessary, as well as commitment and active involvement.

Studies continue to reveal an inadequate metabolic control of diabetes, which seems to be related not only to the patients' characteristics, but also to the care provided and the organization of the health care systems (Nam, Chesla, Stotts, Kroon, \& Janson, 2011). Different types of programs with outcome assessment are being implemented worldwide (Menino et al., 2013), but they still do not allow reaching a consensus on the most effective and replicable intervention strategies and plans in different contexts. We aim to answer this question for quality and sustainability reasons.

In Portugal, although health care centers offer education programs for patients with diabetes, it is recognized that the culture of assessment is still incipient and that studies should be developed to assess the implemented education programs in order to improve the evidence-based knowledge on education in the area of diabetes (Menino et al., 2013). Although there is currently no consensus on the single best therapeutic strategy in the area of diabetes (Menino et al., 2013), therapeutic education is acknowledged as the cornerstone of an effective care in this area (Haas et al., 2014).

The concepts of DSME and therapeutic education are believed to be embodied in the same principles and equivalent to the extent that they are based on the same assumptions. Several relevant entities in the 
area of diabetes have put forward different definitions for the concepts of therapeutic education and DSME. These concepts are all aligned with the same principles related to the central role of the patient, the need to use various complementary strategies (behavioral, psychosocial, educational or psychological, among others), and the importance of continuous support. It is possible to provide continuous support within an adequate network of community care which uses evidence-based practice and models in the area of health care provision to chronic diseases.

DSME is considered to be the ongoing process of facilitating the knowledge, skill and ability necessary for diabetes self-care. It incorporates the needs, goals and life experiences of the person with diabetes, and is guided by evidence-based standards. The activities developed in DSME assists the person with diabetes in implementing and sustaining the necessary behaviors to manage their condition on an ongoing basis (Haas et al., 2014).

The DSME is a process by which people with diabetes, their family and/or significant social contacts are engaged as active participants in the acquisition and application of knowledge, in practical problem-solving and in the acquisition of the coping skills necessary to achieve optimal health outcomes (IDF, 2009).

The American Association of Diabetes Educators (AADE; 2009) recommends that therapeutic education be directed at the following seven self-care behaviors and suggests evidence-based interventions for these behaviors: healthy eating, being active, monitoring, taking medication, problem solving, healthy coping, and reducing risks.

With regard to the role of nursing in the management of this chronic disease, diabetes requires nurses to empower the person with diabetes for self-care, which is translated into quality of life, with self-care promotion being considered as an anticipatory care (Tanqueiro, 2013). Regarding the nurses' role in the management of care provision to the chronic patient, nurses have played a central role in terms of providing information and patient education, building therapeutic relationships with patients, carers and communities, providing continuity of care, using technology to advance care provision, supporting adherence to long-term therapies, and promoting a collaborative practice (International Council of Nurses, 2010).

The role of nurses in the management of chronic diseases has been acknowledged, particularly as educators and in primary health care settings, with documented results specifically in the area of diabetes and in glycemic control, self-care, and patient satisfaction (Glasgow, Orleans, Wagner, Curry, \& Solberg, 2001).

Due to the incipient culture of assessment, and although the importance of nursing care is acknowledged, in particular in what concerns the promotion of self-care through therapeutic education interventions, few studies can be found in the literature that assess the interventions specifically developed by nurses with a view to promoting self-care among people with diabetes.

\section{Research Question}

This study aims to answer the following question: is the Scale of Assessment of the Frequency with which Nurses Develop Therapeutic Education Interventions for self-care behaviors aiming at the person with diabetes valid and reliable?

\section{Methodology}

\section{Participants}

The final instrument was applied to a sample of 104 nurses from a cluster of health care centers (agrupamento de centros de saúde-ACES) of the central region of Portugal who met the inclusion criteria: accepting to participate in the study and providing nursing consultations to diabetic patients. Taking into account the size of the target population (150 nurses from the ACES under study), the response rate was $69.3 \%$.

\section{Instrument}

The data collection instrument was composed of two parts: the first part consisted of questions about the participants' sociodemographic and professional characteristics, whereas the second part was composed of the multidimensional scale of therapeutic education for diabetes self-care behavior. The scale is divided into six dimensions: (a) healthy eating, (b) being active, (c) monitoring, (d) taking medication, (e) problem solving and healthy coping, and (f) reducing risks.

The process of building the scale was preceded by a literature review conducted with the purpose of 
identifying the most important variables for assessing this construct. The search used the key terms Guidelines AND Diabetes AND Education. It was also preceded by a content analysis of the guidelines found in the search with a view to identifying the recommended categories concerning the therapeutic education for self-care in the area of diabetes. The selected guidelines allowed us to identify the process variables relating to the interventions identified as relevant for being associated with the expected outcomes in the area of diabetes. Then, the scale was sent to a group of five experts who analyzed its content validity and face validity.

The group of experts was composed based on the criteria recommended in the literature, with an adaptation of Fehring's criteria (1987). The group of selected nurses had at least 5 years of experience in diabetes care, had a Master's degree in Nursing, and had studies published in this area.

The questions in which the experts reached a 75\% consensus were kept in the scale (Chang, Gardner, Duffield, \& Ramis, 2010). The remaining questions were changed according to the suggestions and the scale was again submitted to the experts for them to comment on its adequacy and clarity. In this second round, an interrater agreement higher than $75 \%$ was reached regarding the questions under analysis, thus we considered that consensus had been reached.

The 34 items included in the six dimensions indicated in the literature were organized into a 5-point Likert-type scale, ranging from Always to Never. The scale aims to assess how often the practices described in the guidelines as desirable practices in the context of education toward the six self-care behaviors (six dimensions) were implemented: healthy eating, being active, monitoring, taking medication, problem solving and healthy coping, and reducing risks.

\section{Procedures and Data Treatment}

This study began after a favorable opinion from the Ethics Committee (opinion number 32543) of the institution where the data were collected and from the Directing Council of the Regional Health Authority (ARS) where the study was conducted. The head nurses of the services where the data were collected were also previously contacted.

Data were statistically processed using Microsoft Word XP and the Statistical Package for the Social Sciences (SPSS), version 19.0 for Windows. For the statistical analysis of data, we used measures of absolute and relative frequency, measures of central tendency, measures of dispersion or variability, Pearson's correlations to assess item homogeneity and Cronbach's alpha as a measure of internal reliability. The construct validity of each dimension was performed using a principal components analysis with orthogonal Varimax rotation. The construct validity of the multidimensional scale was assessed using concurrent and discriminant validity (correlation between each item and the dimension to which it belongs or does not belong).

The participants' anonymity and confidentiality were guaranteed, as well as the compliance with the principles of the Declaration of Helsinki. All ethical and legal principles were followed.

\section{Results}

\section{Sociodemographic and Professional Characterization of the Sample}

The mean age of the sample composed of 104 nurses was $41.3 \pm 8.1$ years, with a maximum age of 62 years and a minimum age of 29 years. As for the years in the profession, the nurses had been working on average for $17.7 \pm 7.8$ years, with $12.4 \pm 7.5$ years of professional experience in the area of diabetes.

Most respondents (39.4\%) worked in a personalized health care unit (Unidade de Cuidados de Saúde Personalizados - UCSP), 25\% worked in a family health unit (Unidade de Saúde Familiar - USF) and 35.6\% answered "Other", having been working in the current unit for $9.4 \pm 8.4$ years.

With regard to the area of diabetes and, more specifically, the frequency of training in this area after the beginning of the professional career, most respondents (60.6\%) mentioned having had training, whereas $39.4 \%$ said that they had attended no training in this area since working as nurses.

\section{Psychometric Characteristics of the Scale}

Reliability was assessed by calculating Cronbach's alpha coefficient $(\alpha)$, as proposed by Pestana and Gageiro (2005). The items with Cronbach's alpha values higher than the total Cronbach's alpha values were excluded. However, it should be noted that we decided to keep items 7, 13,18 and 23 although these items had, in the hundredths, higher Cronbach's 
alpha values than the total Cronbach's $\alpha$ value, as we consider them to be essential for the construct under analysis and the total $\alpha$ did not improve with their exclusion (Table 1).

Thus, we assessed the Cronbach's $\alpha$ for each dimension of the Therapeutic Education for Diabetes Self-Care Behavior (Escala de Educação Terapêutica para o Comportamento de Autocuidado à pessoa com diabetes - ETCAD). The scale showed Cronbah's alpha values between 0.768 and 0.933 for the different dimensions, revealing a reasonable/good internal consistency (Pestana \& Gageiro, 2005).

We observed corrected item-total correlations between 0.391 and 0.834 , varying between moderate to high correlation (Pestana \& Gageiro, 2005), with these values being considered as good according to Streiner and Norman (2008).

Table 1

Homogeneity statistics of the items and Cronbach's alpha coefficient of the six dimensions of the multidimensional ETCAD scale

\begin{tabular}{|c|c|c|c|}
\hline \multirow{2}{*}{\multicolumn{2}{|c|}{ Healtbv eating }} & $r$ if item deleted & \multirow[t]{2}{*}{$\alpha$ If item de } \\
\hline & eating & & \\
\hline 1 & The effects of food on glucose levels & 0.469 & 0.751 \\
\hline 2 & Sources of carbohydrates, proteins and fats & 0.485 & 0.742 \\
\hline 3 & Making healthy food choices & 0.517 & 0.742 \\
\hline 4 & Adjusting portion size & 0.614 & 0.721 \\
\hline 5 & Reading labels & 0.662 & 0.698 \\
\hline 6 & Counting carbohydrates & 0.481 & 0.745 \\
\hline 7 & Preparing meals & 0.416 & 0.776 \\
\hline Tot: & & 0.768 & \\
\hline \multicolumn{4}{|c|}{ Being active } \\
\hline 8 & Analyzing barriers (physical, environmental, psychological and time) & 0.670 & \\
\hline 9 & $\begin{array}{l}\text { Developing an appropriate activity schedule that balances food and medication } \\
\text { with the level of activity }\end{array}$ & 0.670 & \\
\hline Tot: & & 0.802 & \\
\hline \multicolumn{4}{|c|}{ Monitoring } \\
\hline 10 & Helping patients choose and select blood glucose monitoring devices & 0.565 & 0.699 \\
\hline 11 & Timing and frequency of blood glucose monitoring & 0.618 & 0.705 \\
\hline 12 & Interpreting and using the results & 0.581 & 0.708 \\
\hline 13 & Teaching how to regularly check blood pressure & 0.391 & 0.779 \\
\hline 14 & Teaching how to regularly check weight & 0.622 & 0.677 \\
\hline & & 0.758 & \\
\hline \multicolumn{4}{|c|}{ Taking medication } \\
\hline 15 & Teaching for each medication: action, side effects, efficacy and toxicity & 0.711 & 0.785 \\
\hline 16 & $\begin{array}{l}\text { Teaching for each medication: prescribed dosage, timing and frequency of } \\
\text { administration }\end{array}$ & 0.704 & 0.788 \\
\hline 17 & Teaching for each medication: effects of missed or delayed doses & 0.757 & 0.767 \\
\hline 18 & $\begin{array}{l}\text { Teaching for each medication: administration, storage, travel and safety in- } \\
\text { structions }\end{array}$ & 0.547 & 0.851 \\
\hline & & 0.842 & \\
\hline \multicolumn{4}{|c|}{ Problem solving and healthy coping } \\
\hline 19 & Analyzing physical difficulties & 0.730 & 0.926 \\
\hline 20 & Analyzing emotional difficulties & 0.834 & 0.920 \\
\hline 21 & Analyzing cognitive difficulties & 0.802 & 0.922 \\
\hline 22 & Analyzing financial difficulties & 0.756 & 0.925 \\
\hline 23 & Fostering the development of coping strategies & 0.691 & 0.929 \\
\hline 24 & Identifying the patient's motivation for behavioral change & 0.767 & 0.924 \\
\hline 25 & Helping the patient reach attainable goals & 0.607 & 0.934 \\
\hline
\end{tabular}




\section{Reducing risks}

$\begin{array}{llll}28 & \text { Teaching about therapeutic recommendations with a view to reducing risks } & 0.699 & 0.795 \\ 29 & \text { Establishing goals for reducing risks } & 0.645 & 0.803 \\ 30 & \text { Helping to develop smoking cessation skills } & 0.523 & 0.829 \\ 31 & \text { Helping to develop feet examination skills } & 0.496 & 0.825 \\ 32 & \text { Helping to develop blood pressure monitoring skills } & 0.584 & 0.816 \\ 33 & \text { Helping to develop blood glucose self-monitoring skills } & 0.609 & 0.812 \\ 34 & \text { Helping to develop optimal personal care maintenance skills } & 0.643 & 0.803 \\ \text { Total Alpha } & 0.834 & \end{array}$

With regard to the study of construct validity, we performed a factor analysis in all dimensions. In order to maximize item saturation, we conducted an orthogonal rotation using the Varimax method. After successive analyzes, we performed a principal component factor analysis according to the Kaiser-Meyer-Olkin (KMO) measure with factor loadings equal to or greater than 0.30 and interpretability/ significance. We found factor loadings greater than 0.50 , i.e. accounting for at least $25 \%$ of the variance (Pestana \& Gageiro, 2005). The KMO and the Bartlett's test were the two statistical procedures used to assess the quality of inter-variable correlations in order to proceed with the factor analysis, taking into account the assumptions of Pestana and Gageiro (2005).

For each dimension of the scale, we present the commonality coefficient values, which describe the covariance of the item with isolated factors, i.e. the extent to which each item is related to the isolated factors (Almeida \& Freire, 2007). This analysis shows that the items are grouped into a single factor in all dimensions, except for the dimension Problem solving and healthy coping which is divided into two factors.

According to Table 2, based on the KMO value greater than 0.7 for all dimensions, and the significance of Bartlett's test of sphericity $(p<0.001)$, we found a good factor analysis (Pestana \& Gageiro, 2005) in which all variables correlated significantly in all dimensions.

The KMO of all dimensions is greater than 0.7 , which reveals a reasonable factor analysis, "being that values close to zero indicate a weak inter-variable correlation" (Pestana \& Gageiro, 2005, p. 495).

\section{Table 2}

Principal component matrix after Varimax rotation of the items of each dimension of the multidimensional ETCAD scale

\begin{tabular}{lcc}
\hline Item & Principal Factors & Communalities \\
\hline Healthy eating & & 0.533 \\
1 & 0.730 & 0.485 \\
2 & 0.696 & 0.586 \\
3 & 0.765 & 0.626 \\
4 & 0.791 & 0.495 \\
5 & 0.704 & 0.298 \\
6 & 0.546 & 0.249 \\
7 & 0.499 & - \\
$\%$ of variance explained & 54.715 & - \\
KMO & 0.767 & - \\
Bartlett's Sphericity Test & $21 ; p<0.000$ & \\
Being active & & - \\
8 & &
\end{tabular}


Monitoring

Taking medication

$\%$ of variance explained

Problem solving and healthy coping

F1: Problem solving

19

20

21

22

23

F2: Healthy coping

24

25

26

27

$\%$ of variance explained

$$
\mathrm{KMO}
$$

Bartlett's Sphericity Test

Reducing risks

28

29

30

31

32

33

34

$\%$ of variance explained

KMO

Bartlett's Sphericity Test
We also analyzed the convergent-discriminant validity of the items. Based on Table 3, we can state that all items have a higher correlation with the total dimension to which they belong than with the dimension to which they do not belong, which reveals that the organization of the scale and the distribution of items proved adequate and valid in terms of psychometric characteristics (Pestana \& Gageiro, 2005). The value of this correlation was always greater than 0.5 , being considered a reasonable correlation (Pestana \& Gageiro, 2005). 
Table 3

Pearson's correlation between the items and the total of the scale to which they belong and to which they do not belong

\begin{tabular}{|c|c|c|c|c|c|c|}
\hline & F1 & $\mathrm{F} 2$ & F3 & F4 & F5 & F6 \\
\hline 1 & $0.571^{* *}$ & $0.369^{* *}$ & $0.522^{* * *}$ & $0.319^{* *}$ & $0.547^{* * *}$ & $0.402^{* *}$ \\
\hline 2 & $0.618^{* *}$ & $0.286^{* *}$ & $0.331^{* * *}$ & $0.353^{* *}$ & $0.326^{* * *}$ & 0.176 \\
\hline 3 & $0.624^{* *}$ & $0.269^{* *}$ & $0.419^{* * *}$ & $0.314^{* * *}$ & $0.526^{* *}$ & $0.332^{* *}$ \\
\hline 4 & $0.719^{* *}$ & $0.340^{* *}$ & $0.338^{* * *}$ & $0.447^{* *}$ & $0.436^{* * *}$ & $0.389^{* *}$ \\
\hline 5 & $0.789^{* *}$ & $0.388^{* *}$ & $0.410^{* * *}$ & $0.577^{* *}$ & $0.415^{* * *}$ & $0.443^{* *}$ \\
\hline 6 & $0.677^{* *}$ & $0.257^{* *}$ & $0.219^{*}$ & $0.401^{* *}$ & $0.246^{*}$ & $0.306^{* *}$ \\
\hline 7 & $0.661^{* *}$ & $0.317^{* *}$ & $0.216^{*}$ & $0.401^{* *}$ & $0.213^{*}$ & $0.357^{* * *}$ \\
\hline 8 & $0.423^{* *}$ & $0.910^{* *}$ & $0.371^{* * *}$ & $0.349^{* *}$ & $0.449^{* * *}$ & $0.625^{* *}$ \\
\hline 9 & $0.435^{* *}$ & $0.917^{* *}$ & $0.465^{* * *}$ & $0.495^{* *}$ & $0.521^{* * *}$ & $0.620^{* *}$ \\
\hline 10 & $0.218^{*}$ & $0.307^{* *}$ & $0.744^{* *}$ & $0.340^{* *}$ & $0.427^{* * *}$ & $0.319^{* * *}$ \\
\hline 11 & $0.431^{* *}$ & $0.432^{* *}$ & $0.729^{* * *}$ & $0.441^{* *}$ & $0.549^{* * *}$ & $0.379^{* *}$ \\
\hline 12 & $0.363^{* *}$ & $0.345^{* *}$ & $0.710^{* * *}$ & $0.340^{* *}$ & $0.528^{* * *}$ & $0.391^{* *}$ \\
\hline 13 & $0.384^{* *}$ & $0.308^{* *}$ & $0.663^{* *}$ & $0.385^{* *}$ & $0.393^{* *}$ & $0.345^{* *}$ \\
\hline 14 & $0.387^{* *}$ & $0.327^{* *}$ & $0.806^{* *}$ & $0.495^{* *}$ & $0.462^{* * *}$ & $0.380^{* *}$ \\
\hline 15 & $0.498^{* *}$ & $0.323^{* *}$ & $0.447^{* *}$ & $0.853^{* *}$ & $0.527^{* * *}$ & $0.453^{* *}$ \\
\hline 16 & $0.567^{* *}$ & $0.341^{* *}$ & $0.511^{* *}$ & $0.847^{* *}$ & $0.416^{* *}$ & $0.433^{* *}$ \\
\hline 17 & $0.613^{* *}$ & $0.504^{* *}$ & $0.506^{* *}$ & $0.866^{* *}$ & $0.572^{* * *}$ & $0.522^{* *}$ \\
\hline 18 & $0.336^{* *}$ & $0.373^{* *}$ & $0.351^{* *}$ & $0.728^{* *}$ & $0.363^{* * *}$ & $0.378^{* *}$ \\
\hline 28 & $0.431^{* *}$ & $0.445^{* *}$ & $0.410^{* * *}$ & $0.456^{* *}$ & $0.788^{* * *}$ & $0.550^{* *}$ \\
\hline 29 & $0.363^{* *}$ & $0.473^{* *}$ & $0.399^{* * *}$ & $0.392^{* *}$ & $0.748^{* * *}$ & $0.482^{* *}$ \\
\hline 30 & $0.233^{*}$ & $0.298^{* *}$ & $0.306^{* *}$ & $0.384^{* *}$ & $0.698^{* * *}$ & $0.511^{* *}$ \\
\hline 31 & $0.458^{* *}$ & $0.378^{* *}$ & $0.446^{* *}$ & $0.385^{* *}$ & $0.615^{* *}$ & $0.398^{* *}$ \\
\hline 32 & $0.394^{* *}$ & $0.320^{* *}$ & $0.599^{* * *}$ & $0.488^{* *}$ & $0.736^{* * *}$ & $0.538^{* *}$ \\
\hline 33 & $0.455^{* *}$ & $0.342^{* *}$ & $0.571^{* * *}$ & $0.318^{* *}$ & $0.701^{* * *}$ & $0.408^{* *}$ \\
\hline 34 & $0.399^{* *}$ & $0.471^{* *}$ & $0.465^{* * *}$ & $0.417^{* *}$ & $0.747^{* * *}$ & $0.544^{* *}$ \\
\hline 19 & $0.433^{* *}$ & $0.608^{* *}$ & $0.487^{* * *}$ & $0.415^{* *}$ & $0.563^{* * *}$ & $0.786^{* *}$ \\
\hline 20 & $0.457^{* *}$ & $0.608^{* *}$ & $0.490^{* * *}$ & $0.441^{* *}$ & $0.577^{* * *}$ & $0.874^{* *}$ \\
\hline 21 & $0.412^{* *}$ & $0.516^{* *}$ & $0.413^{* * *}$ & $0.378^{* *}$ & $0.548^{* * *}$ & $0.848^{* *}$ \\
\hline 22 & $0.457^{* *}$ & $0.545^{* *}$ & $0.428^{* *}$ & $0.479^{* *}$ & $0.567^{* *}$ & $0.819^{* *}$ \\
\hline 23 & $0.345^{* *}$ & $0.531^{* *}$ & $0.399^{* * *}$ & $0.502^{* *}$ & $0.567^{* * *}$ & $0.764^{* *}$ \\
\hline 24 & $0.401^{* *}$ & $0.514^{* *}$ & $0.313^{* * *}$ & $0.419^{* *}$ & $0.576^{* * *}$ & $0.818^{* *}$ \\
\hline 25 & $0.330^{* *}$ & $0.420^{* *}$ & $0.279^{* * *}$ & $0.385^{* *}$ & $0.467^{* * *}$ & $0.695^{* *}$ \\
\hline 26 & $0.406^{* *}$ & $0.599^{* *}$ & $0.382^{* * *}$ & $0.469^{* *}$ & $0.640^{* * *}$ & $0.836^{* *}$ \\
\hline 27 & $0.491^{* *}$ & $0.632^{* *}$ & $0.391^{* *}$ & $0.441^{* *}$ & $0.516^{* * *}$ & $0.845^{* *}$ \\
\hline
\end{tabular}

F1 = Healthy eating; F2 = Being active; F3 = Monitoring; F4 = Taking medication; F5 = Reducing risks; F6 = Problem solving and healthy coping.

For the six dimensions of the scale, higher mean scores were found in the Reducing risks dimension (4.22 \pm 0.52$)$. On the other hand, the Taking medication dimension had the lowest mean scores $(3.59 \pm 0.66)$. In the remaining dimensions, the values also indicate frequent therapeutic education practices: Healthy eating (3.98 \pm 0.61$)$, Being active (3.74 \pm 0.94$)$, Monitoring (4.18 \pm 0.64$)$, Problem solving and healthy coping $(4.02 \pm 0.72)$.

\section{Discussion}

We examined the psychometric characteristics of the scale with the purpose of producing a valid and reliable tool to measure therapeutic self-care education aiming at the person with diabetes. Initially, the literature supported the items included in the scale. Subsequently, its content was validated by a panel of experts, taking into account the adaptation of 
Fehring's criteria (1987). This version was then applied to 104 nurses who provided nursing consultations to people with diabetes, and, finally, its psychometric characteristics were assessed.

Although we found no scale to assess this construct and allow for the comparison of the results obtained, we believe that, based on the values obtained, this validated scale can be applied in the future with guaranteed consistent results (Coutinho, 2011).

For the several dimensions of the ETCAD, the Cronbach's alpha values between 0.768 and 0.933 show a good/reasonable internal consistency which, associated with the correlations of each item with the total of its dimension between 0.391 and 0.834 , reveal moderate to high correlations (Pestana \& Gageiro, 2005). Therefore, we believe that this is a reliable scale that will provide consistent results in further applications, since reliability is related to the consistency of the results in repeated applications of the scale (Coutinho, 2011).

Based on the factor analysis, the scale also showed an adequate validity, with $\mathrm{KMO}$ values between 0.710 and 0.89 (Bartlett's test, $p<0.001$ ) showing adequate inter-variable correlations for each dimension.

The scale was divided into six dimensions related to the seven self-care behaviors recommended by the AADE (2009). Hill-Briggs and Gemmell (2007) argue that problem-solving is a multidimensional construct encompassing rational problem-solving and coping, which is in line with the factor organization obtained that groups problem-solving and healthy coping.

Self-management education plays a key role in diabetes care. The nurses' role has been increasingly recognized in the management of chronic diseases through empowerment mediated by therapeutic education. Thus, the development of this scale allows identifying the therapeutic education practices on self-care behaviors implemented by nurses, and, subsequently, identifying the nurses' contribution of nurses to health gains.

\section{Conclusion}

Diabetes is a chronic disease that is reaching an epidemic proportion, and there are interventions that have proven to be effective in managing it. Therapeutic self-care education has been considered as the cornerstone toward achieving the desired outcomes and the adoption of specific behaviors aimed at promoting a healthy adaptation to diabetes and maintaining quality of life.

It is important to monitor the interventions developed by nurses in this context from a perspective of quality analysis and with the purpose of establishing goals regarding the care process, taking into account the available evidence and the expected outcomes.

The major objective of this study was to develop a scale to assess the nurses' therapeutic education practices on self-care behaviors, which was achieved through content and facial validity, reliability and validity. After validation, the scale was composed of a total of 34 items organized into six dimensions, proving to be a valid and reliable scale. The identification of self-care education practices developed by nurses will allow adjusting the nurses' care practices to achieve the expected results.

We suggest a wider application of the scale so as to improve its robustness, as well as its application in random samples to determine the generalizability of the research findings.

\section{References}

American Association of Diabetes Educators. (2009). AADE guidelines for the practice of diabetes self-management education and training (DSME/T). The Diabetes Educator, 35(3 suplemento), 85S-107S. doi: 10.1177/0145721709352436

Almeida, L., \& Freire, T. (2007). Metodologia da investigação em psicologia e educação (4a ed.). Braga, Portugal: Psiquilíbrios.

Chang, A. M., Gardner, G. E., Duffield, C., \& Ramis, M. A. (2010). A delphi study to validate an advanced practice nursing tool. Journal of Advanced Nursing, 66(10), 2320-2330. doi: 10.1111/j.1365-2648.2010.05367.x

Correia, L., Boavida, J. M., Almeida, J. P., Cardoso, S. M., Dores, J., Duarte, J. S., ... Raposo, J. (2013). Diabetes: Factos enúmeros 2013: Relatório anual do observatório nacional da diabetes. Retrieved from https://www.dgs.pt/paginaRegisto. aspx?back $=1 \& \mathrm{id}=25163$

Coutinho, C. (2011). Metodologia de investigação em ciências sociais e bumanas: Teoria e prática ( $2^{\mathrm{a}}$ ed.). Coimbra, Portugal: Almedina.

Fehring, R. (1987). Methods to validate nursing diagnosis. Retrieved from http://epublications.marquette.edu/cgi/ viewcontent.cgi?article $=1026 \&$ context $=$ nursing_fac

Glasgow, R. E., Orleans, C., Wagner, E. H., Curry, S. J., \& Solberg, L. I. (2001). Does the chronic care model serve also as a template for improving prevention?. Milbank Quarterly, 79(4), 579-612. doi: 10.1111/1468-0009.00222 
Haas, L., Maryniuk, M., Beck, J., Cox, C. E., Duker, P., Edwards, L., ... Youssef, G. (2014). National standards for diabetes self-management education and support. Diabetes Care, 37(sup.1), S144-S153. doi:10.2337/dc12-1707

Hill-Briggs, F., \& Gemmell, L. (2007). Problem solving in diabetes self-management and control a systematic review of the literature. The Diabetes Educator, 33(6), 1032-1050. doi: $10.1177 / 0145721707308412$

Hollis, M., Glaister, K., \& Lapsley, J. A. (2014). Do practice nurses have the knowledge to provide diabetes self-management education?. Contemporary nurse, 46(2), 234-241.

International Diabetes Federation. (2009). International standards for diabetes education. Retrieved from http:// www.idf.org/files/idf_publications/international_standards for_diabetes_education_EN/index.html\#/2/

International Diabetes Federation. (2013). Diabetes atlas. Retrieved from https://www.idf.org/sites/default/files/ EN_6E_Atlas_Full_0.pdf

International Council of Nurses (2010). Delivering quality, serving communities: Nurses leading chronic care. Retrieved from http://www.icn.ch/images/stories/documents/publications/ ind/indkit2010.pdf
Menino, E., Dixe, M. A., Louro, M. C. M., \& Roque, S. M. B. (2013). Programas de educação dirigidos ao utente com diabetes mellitus tipo 2: Revisão sistemática da literatura. Revista de Enfermagem Referência, 10, 135-143.

Nam, S., Chesla, C., Stotts, N. A., Kroon, L., \& Janson, S. L. (2011). Barriers to diabetes management: Patient and provider factors. Diabetes research and clinical practice, 93(1), 1-9. doi: 10.1016/j.diabres.2011.02.002

National Institute for Clinical Excellence. (2003). Guidance on the use of patient- education models for diabetes. London, United Kingdom: National Institute for Clinical Excellence.

Pestana, M., \& Gageiro, J. (2005). Análise de dados para ciências sociais - A complementariedade do SPSS. Lisboa, Portugal: Edições Sílabo.

Streiner, D., \& Norman, G. (2008). Health measurement scales: A practical guide to their development and use. New York, USA: Oxford University Press

Tanqueiro, M. T. D. O. S. (2013). A gestão do autocuidado nos idosos com diabetes: revisão sistemática da literatura. Revista de Enfermagem Referência, 9, 151-160. doi: 10.12707/ RIII1202 